\title{
Effects of chronic administration of PPAR- $\gamma$ ligand rosiglitazone in Cushing's disease
}

\author{
Bruno Ambrosi ${ }^{1}$, Chiara Dall'Asta ${ }^{1}$, Salvatore Cannavò ${ }^{2}$, Rossella Libè ${ }^{3}$, Teresa Vigo ${ }^{2}$, Paolo Epaminonda ${ }^{3,4}$, \\ Iacopo Chiodini ${ }^{4}$, Stefano Ferrero ${ }^{2}$, Francesco Trimarchi ${ }^{2}$, Maura Arosio ${ }^{3,4}$ and Paolo Beck-Peccoz ${ }^{4}$ \\ ${ }^{1}$ Endocrinology Unit, Department of Medical and Surgical Sciences, University of Milan, Istituto Policlinico San Donato, San Donato Milanese, Milan, \\ Italy, ${ }^{2}$ Endocrinology Unit, Department of Medicine and Pharmacology, University of Messina, Messina, Italy, ${ }^{3}$ Institute of Endocrine Sciences, \\ University of Milan, Ospedale Maggiore IRCCS, Milan, Italy, ${ }^{4}$ Endocrinology Unit, Ospedale San Giuseppe-Fatebenefratelli, AFaR, Milan, Italy and \\ ${ }^{5}$ Department of Pathology, University of Milan, Ospedale Maggiore IRCCS and A.O. San Paolo, Milan, Italy \\ (Correspondence should be addressed to B Ambrosi; Email: bruno.ambrosi@unimi.it)
}

\begin{abstract}
Objective: Rosiglitazone, a thiazolidinedione compound with peroxisome proliferator-activated receptor- $\gamma$ (PPAR- $\gamma$ )-binding affinity, is able to suppress adrenocorticotropic hormone (ACTH) secretion in treated mice and in AtT20 pituitary tumor cells. These observations suggested that thiazolidinediones may be effective as therapy for Cushing's disease (CD).

Patients and methods: Rosiglitazone $(8 \mathrm{mg} /$ day) was administered to 14 patients with active CD (13 women, one man, 18-68 years). Plasma ACTH, serum cortisol (F) and urinary free cortisol (UFC) levels were measured before and then monthly during rosiglitazone administration.

Results: In six patients a reduction of ACTH and F levels and a normalization of UFC were observed 30-60 days after the beginning of rosiglitazone administration: there was a significant difference between basal and post-treatment values for UFC $(1238 \pm 211$ vs $154 \pm 40 \mathrm{nmol} / 24 \mathrm{~h}, P<0.03)$,

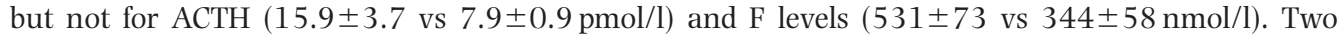
of six cases, followed up for 7 months, showed a mild clinical improvement. Eight patients were nonresponders after 30-60 days of rosiglitazone treatment: their ACTH, F and UFC levels did not differ before and during drug administration. Immunohistochemical analysis of pituitary tumors removed from two responder and two nonresponder patients showed a similar intense immunoreactivity for PPAR- $\gamma$ in about $50 \%$ of cells.

Conclusions: The administration of rosiglitazone seems able to normalize cortisol secretion in some patients with $\mathrm{CD}$, at least for short periods. Whether the activation of PPAR- $\gamma$ by rosiglitazone might be effective as chronic pharmacologic treatment of CD needs a more extensive investigation through a randomized and controlled study.
\end{abstract}

European Journal of Endocrinology 151 173-178

\section{Introduction}

Peroxisome proliferator-activated receptor- $\gamma$ (PPAR- $\gamma)$ is one of the isoforms of the PPAR family of nuclear hormone receptors, and it acts as a transcription factor translating several stimuli to changes in the expression of genes $(1,2)$. Besides the well-known established effects of thiazolidinediones on adipocyte differentiation and insulin sensitivity, it has been shown that synthetic PPAR- $\gamma$ ligands also inhibit tumor cell growth $(3,4)$. Rosiglitazone is a thiazolidinedione antidiabetic agent with a great PPAR- $\gamma$ binding affinity and antihyperglycemic activity (5).

Heaney and coworkers (6) recently reported the abundant expression of PPAR- $\gamma$ in human corticotropinomas and observed that the thiazolidinedione compound rosiglitazone can suppress adrenocorticotropic hormone (ACTH) and corticosterone secretion in treated mice. In addition, rosiglitazone either alone or given before $\mathrm{CRH}$ abolished basal and corticotropinreleasing hormone (CRH)-induced proopiomelanocortin (POMC) transcription in mouse corticotroph pituitary tumor (AtT20) cells (6). On the basis of these findings, the same authors suggested that thiazolidinediones might be effective as therapy for Cushing's disease, a condition in which successful treatment is a challenge. In fact, pituitary adenomectomy by transsphenoidal surgery achieves a cure rate in $70-80 \%$ of patients, while a recurrence, defined as the reappearance of tumor and/or hormonal hypersecretion in previously cured patients, is seen in nearly $13-25 \%$ of the cases and its rate progressively increases over the years (7-9). Since, at present, no pharmacologic agents are effective in the management of Cushing's disease, the preliminary positive results of rosiglitazone chronic administration in two patients (10) prompted us to 
study the possible effectiveness of the drug in the treatment of patients with pituitary corticotropinomas. Very recently, we demonstrated that the acute administration of rosiglitazone did not influence basal or CRHstimulated ACTH and cortisol levels in active Cushing's disease (11); nevertheless, although we are unaware of other similar experiences, a group of such patients underwent a pharmacologic approach with the thiazolidinedione compound for a short time. In addition, the expression of PPAR- $\gamma$ in some excised corticotropinomas was evaluated by immunohistochemistry.

\section{Patients and methods}

\section{Subjects}

Fourteen patients (13 women and one man, aged 1868 years) were studied (Table 1). All patients had active Cushing's disease; seven of them were untreated (case nos. 1, 2, 4, 9, 11, 12 and 14), and seven had undergone unsuccessful transsphenoidal pituitary surgery (case nos 3, 5-8, 10 and 13). The diagnosis of Cushing's disease was made on the basis of clinical features and standard hormonal criteria: high urinary free cortisol (UFC) excretion, normal or high plasma ACTH and serum cortisol levels, absent suppression after low-dose dexamethasone tests (1 mg orally overnight and/or $2 \mathrm{mg} /$ day orally for $48 \mathrm{~h}$ ) but adequate suppression after high-dose dexamethasone tests $(8 \mathrm{mg}$ orally overnight and/or $8 \mathrm{mg} /$ day orally for $48 \mathrm{~h}$ ). A positive $\mathrm{ACTH} /$ cortisol response after $\mathrm{CRH}$ and desmopressin helped to differentiate the pituitary origin of the syndrome. Moreover, nuclear magnetic resonance imaging (MRI) and/or high-resolution computed tomography
(CT) of the sellar region showed a pituitary microadenoma in 11 of 14 patients (case nos. 3-10 and 1214). In the previously operated patients, the histologic examination confirmed the existence of adenomatous tissue, with positive staining for ACTH at immunohistochemical analysis. A histologic confirmation was also obtained in the four patients who underwent pituitary surgery after rosiglitazone treatment.

Four patients (nos. 1, 2, 4 and 12) had type 2 diabetes mellitus and five had insulin resistance (nos. 6 , 10 and $12-14)$.

\section{Study protocol}

Before treatment, plasma ACTH, serum cortisol levels and UFC excretion were measured. In all patients, besides a routine laboratory examination, blood glucose, insulin and glycosylated hemoglobin $\left(\mathrm{HbA}_{1} \mathrm{c}\right)$ levels were also determined. Venous blood samples for all determinations were drawn in fasting condition between 0800 and $0900 \mathrm{~h}$. Insulin sensitivity indices (HOMA and QUICKI) were calculated.

After they granted informed consent, all patients were given rosiglitazone in the morning; the daily dose was $8 \mathrm{mg}$ p.o. for all patients except for patients 2 and 8, in whom the dose was augmented to $16 \mathrm{mg}$ p.o. after 3 and 2 months respectively. The patients were seen after 15 days and then monthly, whenever possible, for clinical and hormonal evaluation.

\section{Hormonal assays}

Plasma ACTH levels were measured in duplicate by the commercially available ILMA method (Nichols Institute

Table 1 Clinical and hormonal data of patients with Cushing's disease in basal conditions and after 30/60 days of treatment with rosiglitazone (nadir).

\begin{tabular}{|c|c|c|c|c|c|c|c|c|c|c|c|}
\hline \multirow[b]{2}{*}{ Patient no. } & \multirow[b]{2}{*}{ Age/sex } & \multirow[b]{2}{*}{ BMI $\left(\mathrm{kg} / \mathrm{m}^{2}\right)$} & \multirow[b]{2}{*}{ MRI/CT } & \multicolumn{2}{|c|}{$\begin{array}{l}\mathrm{ACTH}^{\star} \\
(\mathrm{pmol} / \mathrm{l})\end{array}$} & \multicolumn{2}{|c|}{$\begin{array}{l}\text { Cortisol* } \\
(\mathrm{nmol} / \mathrm{l})\end{array}$} & \multicolumn{2}{|c|}{$\begin{array}{c}\text { UFC } \\
(\mathrm{nmol} / 24 \mathrm{~h})\end{array}$} & \multirow{2}{*}{$\begin{array}{c}\text { Length of } \\
\text { treatment (months) }\end{array}$} & \multirow[b]{2}{*}{ Outcome } \\
\hline & & & & basal & nadir & basal & nadir & basal & nadir & & \\
\hline 1 & $59 / F$ & 24.7 & neg & 18.0 & 9.3 & 508 & 166 & 1165 & 199 & 7 & resp. \\
\hline 2 & $68 / F$ & 28.0 & neg & 14.1 & 11.7 & 662 & 346 & 1565 & 124 & 7 & resp. \\
\hline 3 & $42 / F$ & 22.0 & pos & 32.1 & 4.6 & 475 & 483 & 660 & 237 & 2 & resp. \\
\hline 4 & $60 / F$ & 23.1 & pos & 8.1 & 8.0 & 522 & 433 & 2103 & 267 & 2 & resp. \\
\hline 5 & $52 / F$ & 28.8 & pos & 16.4 & 7.3 & 773 & 230 & 974 & 34 & 2 & resp. \\
\hline 6 & $34 / F$ & 35.8 & pos & 6.5 & 6.4 & 248 & 320 & 963 & 48 & 1 & resp. \\
\hline 7 & $22 / F$ & 27.3 & pos & 16.3 & 9.9 & 604 & 433 & 1223 & 1399 & 4 & non resp. \\
\hline 8 & $34 / F$ & 25.0 & pos & 17.8 & 17.5 & 563 & 593 & 3003 & 878 & 3 & non resp. \\
\hline 9 & 29/M & 26.7 & pos & 12.8 & 9.9 & 425 & 483 & 389 & 693 & 2 & non resp. \\
\hline 10 & $18 / F$ & 28.9 & pos & 11.2 & 7.4 & 563 & 577 & 1138 & 1107 & 2 & non resp. \\
\hline 11 & $33 / F$ & 40.3 & neg & 5.1 & 4.4 & 795 & 894 & 359 & 359 & 1 & non resp. \\
\hline 12 & $66 / F$ & 27.7 & pos & 5.8 & 7.1 & 549 & 524 & 358 & 356 & 1 & non resp. \\
\hline 13 & $32 / F$ & 33.8 & pos & 6.2 & 7.2 & 328 & 690 & 2737 & 2542 & 1 & non resp. \\
\hline 14 & $43 / F$ & 40.4 & pos & 9.0 & 5.1 & 480 & 494 & 483 & 334 & 1 & non resp. \\
\hline
\end{tabular}

* Mean of at least 3-4 determinations.

MRI/CT: magnetic resonance imaging/computerized tomography; pos/neg: presence/absence of pituitary tumor; resp./non resp.: responsive or nonresponsive patient to treatment with rosiglitazone.

Normal ranges: ACTH (0.7-13.3 pmol/l), cortisol (140-700 nmol/l), UFC (35-275 nmol/24 h). 
Diagnostics, San Juan Capistrano, CA, USA). Serum and UFC levels (after extraction with dichloromethane) were measured by the IFMA method (AutoDelfia Wallac, Turku, Finland). The intra- and the interassay coefficients of variation for both assays were $<5 \%$ and $<10 \%$ respectively. Reference ranges were as follows: ACTH $0.7-13.3 \mathrm{pmol} / \mathrm{l}$, cortisol 140$700 \mathrm{nmol} / \mathrm{l}$ and UFC $35-275 \mathrm{nmol} / 24 \mathrm{~h}$.

\section{Immunohistochemistry}

PPAR- $\gamma$ immunostaining was performed on four formalin-fixed, paraffin-embedded corticotropinoma samples (from patients 3, 5, 9 and 14) after microwave pretreatment $(2 \times 6-\mathrm{min}$ cycles in sodium citrate $(\mathrm{pH}$ 6.0) by incubating sections overnight at $4{ }^{\circ} \mathrm{C}$ with a specific monoclonal antibody for PPAR- $\gamma$ (Up-State, Charlottesville, VA, USA) at a working dilution of 1:50. Antigen-antibody was detected by the DAKO ChemMate En Vision kit (DAKO A/S, Glostrup, Denmark) according to the manufacturer's instructions. Sections were then stained with 3,3'-diaminobenzidine substrate and quickly counterstained with Meyer's hematoxylin. As positive control, human normal breast tissue was used.

\section{Statistical analysis}

Data are expressed as mean \pm s.E. Statistical analysis was performed by Student's t-test for paired data.

\section{Results}

\section{Hormonal and clinical effects}

In six of the 14 treated patients, rosiglitazone caused a reduction of cortisol secretion (Table 1): in these cases (nos. 1-6) the drug was given for 30-210 days. As shown in Fig. 1, a lowering of plasma ACTH and cortisol levels and a normalization of UFC was observed 30-60 days after the beginning of rosiglitazone administration. Among these responsive patients, a difference between basal and post-treatment hormonal values was found: however, this difference reached statistical significance only for UFC (1238 211 vs $154 \pm 40$ $\mathrm{nmol} / 24 \mathrm{~h}, \mathrm{P}<0.03)$, but not for ACTH $(15.9 \pm 3.7$ vs $7.9 \pm 0.9 \mathrm{pmol} / \mathrm{l})$ and cortisol levels (531 \pm 73 vs $344 \pm 58 \mathrm{nmol} / \mathrm{l}$ ). Two of these six patients ( 1 and 2 ) were followed up for 7 months (Fig. 1), and a mild improvement in clinical features was observed. In patient 1, ACTH, cortisol and UFC levels fell within
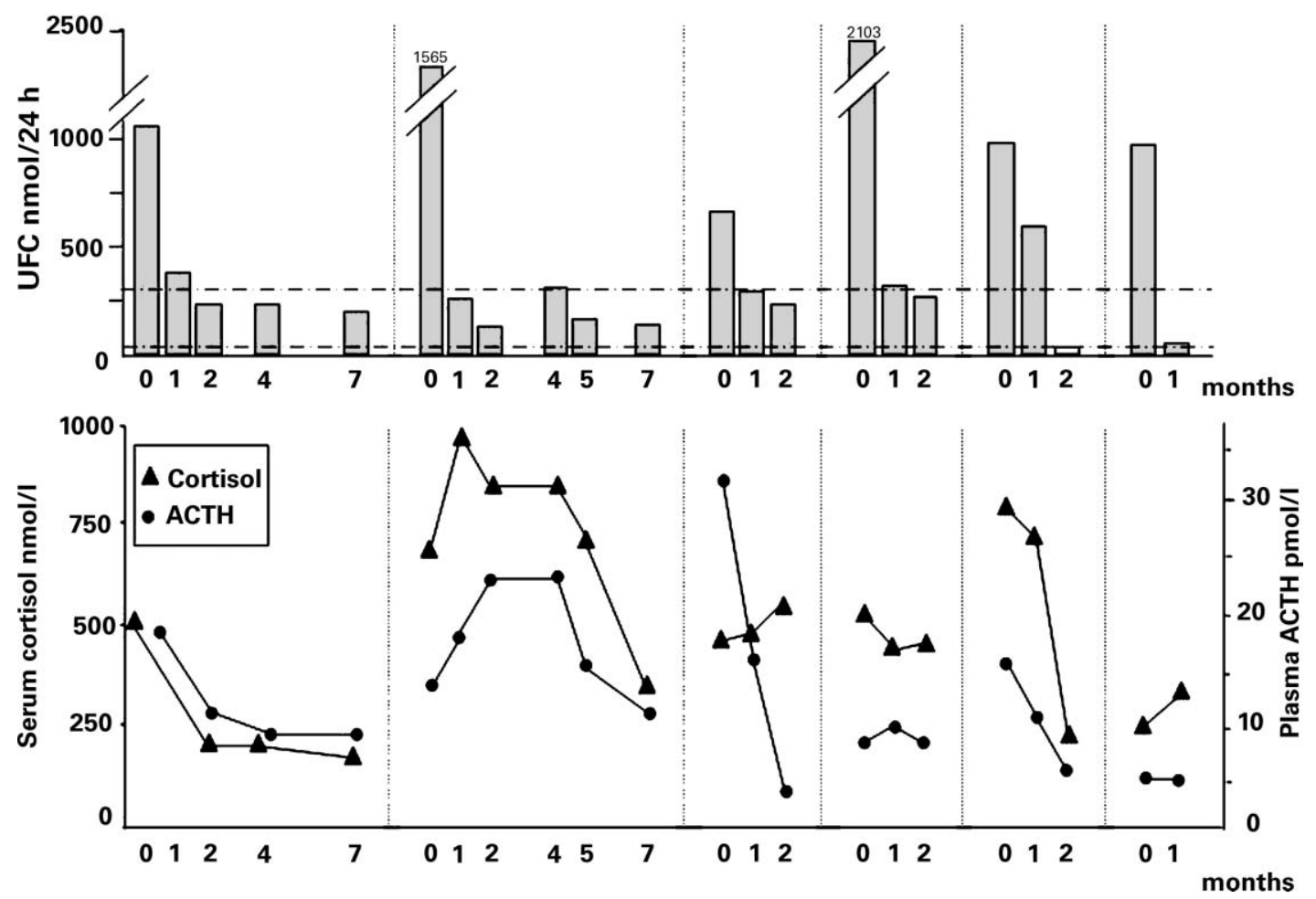

Figure 1 Urinary free cortisol (UFC), plasma ACTH and serum cortisol levels at baseline and after 1, 2, 4, 5 and 7 months of rosiglitazone administration in patients with Cushing's disease responsive to the treatment. Dotted lines in the upper panel indicate the UFC normal range. 
normal limits at month 2 and remained normal. In patient 2 , UFC values were normalized by rosiglitazone after 30 days, but they rose again at month 4; meanwhile, high ACTH and cortisol levels persisted unchanged. Therefore, the rosiglitazone dose was increased up to $16 \mathrm{mg} /$ day, and a full normalization of ACTH, cortisol and UFC levels was obtained at months 5-7. In patient 3, the hormonal pattern rapidly normalized, but the medication was discontinued, owing to a rise of cholesterol levels to $409 \mathrm{mg} / \mathrm{dl}$. Two women (nos. 4 and 5) received rosiglitazone for 2 months while awaiting their scheduled pituitary surgery: in both patients, UFC excretion, as well as ACTH/ cortisol values, normalized. In patient 6 , a sustained reduction in UFC excretion was observed already after 30 days. Overall, up to now, three patients (nos. 1, 2 and 6) are still maintained on rosiglitazone treatment, and the follow-up is continuing.

Eight patients were considered nonresponders (Table 1, Fig. 2). In fact, their ACTH, cortisol and UFC levels did not differ before and during rosiglitazone administration $(10.5 \pm 1.7$ vs $8.7 \pm 1.5 \mathrm{pmol} / \mathrm{l}, 538 \pm 49$ vs $598 \pm 49 \mathrm{nmol} / \mathrm{l}$ and $1211 \pm 383$ vs $958 \pm 264$ $\mathrm{nmol} / 24 \mathrm{~h}$ respectively). Notably, in patient 8 , UFC excretion greatly decreased at month 1 (from 3003 to $878 \mathrm{nmol} / 24 \mathrm{~h}$ ), but neither a subsequent fall nor a normalization was obtained, although the drug dose was augmented to $16 \mathrm{mg} /$ day.

\section{Immunohistochemistry}

The four surgically removed corticotropinomas showed a strong immunoreactivity for PPAR- $\gamma$ in about $50 \%$ of the cells. No difference in the percentage of positive cells in tumors removed from the responder (nos. 3 and 5) and nonresponder (nos. 9 and 14) patients was observed. As already reported (6), immunoreactivity was definitely stronger in tumoral cells than in the surrounding normal pituitary.

\section{Metabolic modifications and drug tolerance}

Patient 1 had type 2 diabetes mellitus treated with human insulin, which was withdrawn during rosiglitazone. Rosiglitazone improved insulin sensitivity in two cases (no. 2: HOMA from 8.1 to 2.7, QUICKI from 0.284 to 0.328 ; no. 6: HOMA from 4.9 to 3.8 , QUICKI from 0.303 to 0.313 ) and the glycemic control in patient 4 . In two out of six responsive patients (nos. 3 and 5), insulin sensitivity indices were normal in basal conditions and did not change during treatment (no. 3: HOMA from 1.4 to 1.9, QUICKI from 0.362 to 0.343 ; 5 : HOMA from 0.6 to 0.4 , QUICKI from 0.368 to 0.434 ). Among nonresponsive patients, no substantial changes in insulin sensitivity indices were seen.
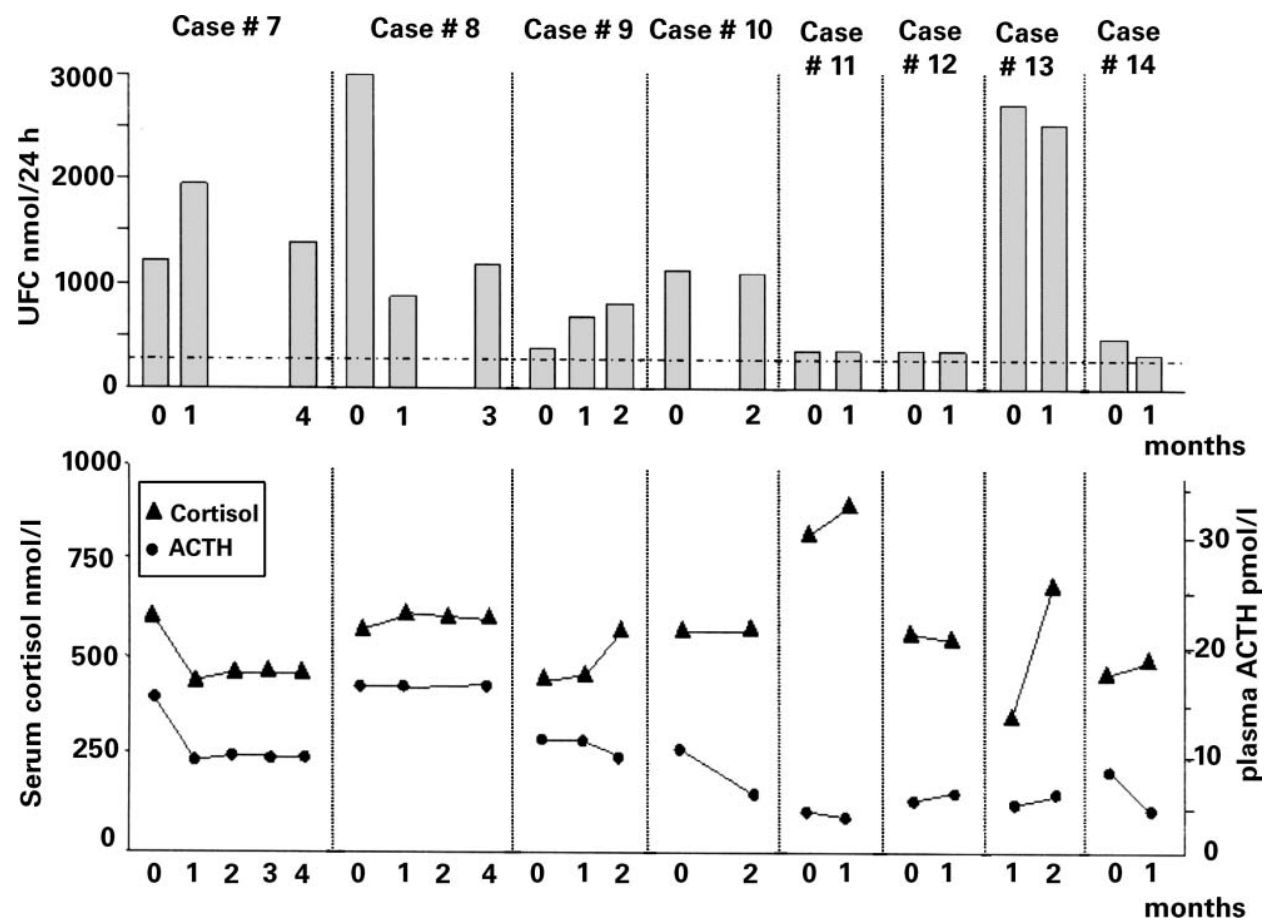

Figure 2 Urinary free cortisol (UFC), plasma ACTH and serum cortisol levels at baseline and after 1, 2, 3 and 4 months of rosiglitazone administration in patients with Cushing's disease nonresponsive to the treatment. Dotted line in the upper panel indicates the upper normal limit for UFC. 
With the exception of hypercholesterolemia in patient 3, none of the patients showed clinical or biochemical signs of drug toxicity.

\section{Discussion}

The treatment of Cushing's disease is a challenge for both endocrinologists and neurosurgeons. Pituitary adenomectomy is the therapy of choice, achieving a $70-80 \%$ cure rate, but disease may recur in nearly $13-25 \%$ of the cases, and recurrence progressively increases over the years (7-9). Although several neurotransmitters and neuropeptides influence ACTH secretion, currently available medical approaches offer little therapeutic success: the administration of neuroactive drugs acting at the hypothalamic-pituitary level (such as bromocriptine, cyproheptadine, cabergoline and valproic acid) seldom shows clinical efficacy and, above all, the long-term responsivity is low (12).

Recently, Heaney and coworkers demonstrated that rosiglitazone inhibits ACTH and corticosterone secretion in treated mice, and suggested that thiazoledinediones may be effective as therapy for Cushing's disease $(6,13)$. In the present study, rosiglitazone was chronically administered in a group of patients with Cushing's disease, in order to evaluate its capability to reduce ACTH and cortisol secretion. Indeed, about $40 \%$ of them showed a reduction of UFC after $1-2$ months of treatment, and an almost apparent normalization of UFC occurred in six cases. It is worth noting that in responsive patients rosiglitazone positively influenced cortisol secretion already after a short period of time. Very recently, the effects of rosiglitazone administration in two patients with Cushing's disease have been briefly reported: the treatment (for 3-12 weeks) was able to reduce UFC excretion by $55 \%$ in one patient and to normalize it in the other (10).

Our data show a more evident influence of rosiglitazone on cortisol secretion than on ACTH secretion, and this is in line with several observations. In fact, it was previously demonstrated that PPAR- $\gamma$ agonists inhibit ovarian steroidogenesis (14); in addition, a direct effect of rosiglitazone on the steroidogenic enzymes P450c17 and 3 3 -hydroxysteroid dehydrogenase was proven by in vitro studies (15). These androgen-lowering effects may further explain the documented clinical efficacy of thiazolidinediones in ameliorating hyperandrogenism in women with polycystic ovarian syndrome $(14,16)$. Moreover, the potential role of thiazolidinediones in ameliorating Cushing's disease is supported by the observations that these drugs antagonize the action of glucocorticoids on target organs, with respect to multiple metabolic effects (17). Consistent with the view that rosiglitazone may reduce cortisol secretion by different mechanisms and sites of action, no difference in the level of PPAR- $\gamma$ expression between tumors removed from responder and nonresponder patients was observed. These data, although obtained in a very small series of tumors, might suggest that the levels of receptor expression in pituitary tumors did not represent the critical event determining the variable inhibition of cortisol secretion induced by PPAR- $\gamma$ agonists. In our experience, apart from the expected improvement of glucose metabolism in two diabetic patients, some clinical features showed only a tendency to slow regression.

Finally, it is conceivable that the long-term effectiveness of rosiglitazone on hormone secretion might also be due to the induction of G0-G1 cell-cycle arrest and apoptosis by PPAR- $\gamma$ ligands, as shown in secreting and nonfunctioning pituitary adenomas (13).

It is relevant that before starting the chronic administration of rosiglitazone to hypercortisolemic patients, the acute effects of the thiazolidinedione compound on ACTH and cortisol secretion were evaluated (11) and, interestingly, no significant hormonal changes were observed. The biochemical efficacy of rosiglitazone in some patients in whom the acute administration of the drug was unable to reduce ACTH/cortisol levels (11) further confirms that the hypothalamic-pituitaryadrenal axis response to acute testing is often misleading. Thus, when dealing with neuromodulatory compounds meant to reduce corticotropin secretion, it is noteworthy that no predictive criteria for therapeutic outcome can be given.

In conclusion, the documented effects of PPAR- $\gamma$ agonists on steroidogenesis and on the peripheral activity of cortisol suggest that the effectiveness of this drug in the treatment of Cushing's disease needs a more extensive evaluation through a randomized and controlled study. Interestingly, our data show that, at least in some patients, there is a favorable response to rosiglitazone in terms of hormonal modifications, but the value of the drug in the management of ACTHdependent Cushing's disease is far from being proved. However, its administration may be attempted as an adjunctive tool in cases of unsuccessful surgery or if the patient cannot safely undergo operation.

\section{Acknowledgements}

This work was partially supported by research grants from FIRST funds of the University of Milan.

\section{References}

1 Issemann I \& Green S. Activation of a member of the steroid hormone receptor superfamily by peroxisome proliferators. Nature $1999347645-660$.

2 Rocchi S \& Auwerx J. Peroxisome proliferator-activated receptorgamma: a versatile metabolic regulator. Annals of Medicine 1999 $31342-351$.

3 Elstner E, Muller C, Koshizuka K, Williamson EA, Park D, Asou H, Shintaku P, Said JW, Heber D \& Koeffler HP. Ligands for peroxisome proliferator-activated receptor- $\gamma$ and retinoic acid receptor 
inhibit growth and induce apoptosis of human breast cancer cells in vitro and in BNX mice. PNAS 199895 8806-8811.

4 Kubota T, Koshizuka K, Williamson EA, Asou H, Said JW, Holden S, Miyoshi I \& Koeffler HP. Ligand for peroxisome proliferator-activated receptor- $\gamma$ (troglitazone) has potent anti-tumor effects against prostate cancer both in vitro and in vivo. Cancer Research $1998583344-3352$.

5 Goldstein BJ. Rosiglitazone. International Journal of Clinical Practice $200054333-337$.

6 Heaney AP, Fernando M, Yong WH \& Melmed S. Functional PPAR- $\gamma$ receptor is a novel therapeutic target for ACTH-secreting pituitary adenoma. Nature Medicine 20028 1281-1287.

7 Bochicchio D, Losa M. Buchfelder M and the European Cushing's Disease Survey Study Group. Factors influencing the immediate and late outcome of Cushing's disease treated by transsphenoidal surgery: a retrospective study by the European Cushing's Disease Survey Group. Journal of Clinical Endocrinology and Metabolism $1995803114-3120$.

8 Invitti C, Pecori Giraldi F, De Martin M, Cavagnini F and the Study Group of the Italian Society of Endocrinology on the Pathophysiology of the Hypothalamic-Pituitary-Adrenal Axis. Diagnosis and management of Cushing's syndrome: results of an Italian multicentre study. Journal of Clinical Endocrinology and Metabolism 199984 440-448.

9 Arnaldi G, Angeli A, Atkinson AB, Bertagna X, Cavagnini F, Chrousos GP, Fava GA, Findling JW, Gaillard RC, Grossman AB, Kola B, Lacroix A, Mancini T, Mantero F, Newell-Price J, Nieman LK, Sonino N, Vance ML, Giustina A \& Boscaro M. Diagnosis and complications of Cushing's syndrome: a consensus statement. Journal of Clinical Endocrinology and Metabolism 2003 88 5593-5602.

10 Heaney AP, Drange MR \& Melmed S Functional PPAR- $\gamma$ receptor is a novel therapeutic target for ACTH-secreting pituitary adenomas (Cushing's disease). The Endocrine Society's 85th
Annual Meeting, 19-22 June, Philadelphia 2003, OR7-4: (abstract).

11 Cannavò S, Ambrosi B, Chiodini I, Vigo T, Russo A, Milici C, Barbetta L, Dall'Asta C, Adda G \& Arosio M. Baseline and CRHstimulated ACTH and cortisol levels after administration of the PPAR- $\gamma$ ligand, rosiglitazone, in Cushing's disease. Journal of Endocrinological Investigation 200427 (In Press).

12 Nieman LK. Medical therapy of Cushing's disease. Pituitary 2002 $577-82$.

13 Heaney AP, Fernando MH \& Melmed S. PPAR- $\gamma$ receptor ligands: a novel therapy for pituitary tumors. Journal of Clinical Investigation 2003111 1381-1388.

14 Veldhuis JD, Zhang G \& Garmey JC. Troglitazone, an insulin-sensitizing thiazoledinedione, represses combined stimulation by LH and insulin of de novo androgen biosynthesis by thecal cells in vitro. Journal of Clinical Endocrinology and Metabolism 200287 $1129-1133$.

15 Arlt W. Auchus RJ \& Miller WL. Thiazoledinediones but not metformin directly inhibit the steroidogenic enzymes P450c17 and $3 \beta$-hydroxysteroid dehydrogenase. Journal of Biological Chemistry 2001276 16767-16771.

16 Mitwally MF, Witchel SF \& Casper RF. Troglitazone: a possible modulator of ovarian steroidogenesis. Journal of the Society for Gynecologic Investigation 20029 163-167.

17 Willi SM, Kennedy A, Wallace P, Ganaway E, Rogers NL \& Garvey WT. Troglitazone antagonizes metabolic effects of glucocorticoids in humans. Effects on glucose tolerance, insulin sensitivity, suppression of free fatty acids and leptin. Diabetes $2002 \mathbf{5 1}$ 2895-2902.

Received 29 March 2004

Accepted 6 April 2004 